\title{
Eficacia del tratamiento y la profilaxis de la gripe con oseltamivir o
} zanamivir

\author{
Eficaccy of influenza treatment and prophylaxis with oseltamivir or zanamivir
}

\section{Objetivo}

Describir los potenciales daños y beneficios de la prescripción de oseltamivir y zanamivir para el tratamiento y la profilaxis de la influenza.

\section{Diseño}

Revisiónes sistemáticas.

\section{Fuentes}

Informes de ensayos clínicos, bases de datos electrónicas, registros de ensayos clínicos, archivos regulatorios y correspondencia con la industria farmacéutica.

\section{Selección de estudios}

Ensayos clínicos controlados y aleatorizados (ECCA) de tratamiento y profilaxis que hubieran incluido adultos y niños sanos o con enfermedades crónicas, expuestos de forma natural a la gripe, con o sin síntomas. Fueron excluidos los estudios abiertos, los estudios post marketing, y los que habían incluido pacientes con infección por el virus de la inmunodeficiencia (HIV) y/o cáncer.

\section{Extracción de datos}

Un primer revisor evaluó si el estudio cumplía con los criterios de inclusión y exclusión y un segundo evaluador, que su reporte fuera completo a través de la lista de cotejo CONSORT, así como su validez interna y externa. A través de una entrevista personal con los autores fueron analizados nuevamente los datos estimándose la probabilidad de sesgos.

\section{Resultados}

Se observó alto riesgo de sesgo de deserción* y de información* en los trabajos que habían evaluado Oseltamivir y alto riesgo de selección* y ejecución* en los que habían evaluado zanamivir.

Las tablas 1 y 2 resumen los principales resultados respecto de la eficacia de ambas drogas para el tratamiento de los pacientes con gripe y para la profilaxis de las personas expuestas a individuos enfermos.

Tabla 1: eficacia del tratamiento con oseltamivir o zanamivir para el alivio sintomático y para prevención del desarrollo de nemonía en pacientes con gripe.

\begin{tabular}{|c|c|c|c|c|c|}
\hline & & \multicolumn{2}{|c|}{$\begin{array}{l}\text { Cambios en la duración de los sintomas } \\
\text { atribuibles al uso de la droga (IC95\%) }\end{array}$} & \multicolumn{2}{|c|}{$\begin{array}{l}\text { Riesgo de desarrollar neumonía verificada por } \\
\text { el equipo investigador (RR e IC95\%) }\end{array}$} \\
\hline & & Oseltamivir & Zanamivir & Oseltamivir & Zanamivir \\
\hline \multirow[t]{2}{*}{ Tratamiento } & Adultos & $\begin{array}{c}-16,8 \mathrm{~h} \\
(-8,4 \mathrm{a}-25,1)\end{array}$ & $\begin{array}{c}-14,4 h \\
(-9,4 a-19,4)\end{array}$ & $\begin{array}{c}0,69 \\
(0,33 \text { a } 1,44)\end{array}$ & $\begin{array}{c}1,02 \\
(0,35 \text { a } 3,02)\end{array}$ \\
\hline & Niños $^{a}$ & $\begin{array}{c}-29 h \\
(-12 a-47)\end{array}$ & $\begin{array}{c}-24,9 \\
(-55 \text { a } 3,6)\end{array}$ & $\begin{array}{c}1,06 \\
(0,62 \text { a } 1,83)\end{array}$ & $\begin{array}{c}0,53 \\
(0,12 \text { a } 2,38)\end{array}$ \\
\hline
\end{tabular}

${ }^{a}$ Sin diferencias estadísticamente significativas en niños con asma (p: 0,53; I2: 75\%). ${ }^{\mathrm{b}}$ Solo pudo documentarse una reducción a casi la mitad (RR: 0,$55 ; 0,33$ a 0,9) de la probabilidad de desarrollar "neumonía no verificada" por el equipo investigador para oseltamivir y de un 70\%" (RR: 0,30; IC95\%: 0,11 a 0,80 ) para zanamivir.

Tabla 2: eficacia de la profilaxis con oseltamivir o zanamivir para la prevención del desarrollo de gripe sintomática.

\begin{tabular}{|c|c|c|c|}
\hline & & \multicolumn{2}{|c|}{ Riesgo de desarrollar gripe sintomática (RR e IC95\%) } \\
\hline & & Oseltamivir & Zanamivir \\
\hline \multirow[t]{2}{*}{ Profilaxis } & $\begin{array}{c}\text { Pre- } \\
\text { exposición }\end{array}$ & $\begin{array}{c}0,45 \\
(0,3 \text { a } 0,67) \\
\text { NNT: } 33\end{array}$ & $\begin{array}{c}0,39 \\
(0,22 \text { a } 0,7) \\
(\text { NNT: } 51)\end{array}$ \\
\hline & $\begin{array}{c}\text { Post- } \\
\text { exposición }\end{array}$ & $\begin{array}{c}0,2 \\
(0,009 \text { a } 0,44) \\
\text { NNT:7 }\end{array}$ & $\begin{array}{c}0,22 \\
(0,13 \text { a } 0,36) \\
\text { NNT:7 }\end{array}$ \\
\hline
\end{tabular}

En adultos, el tratamiento con oseltamivir no disminuyó la probabilidad de ser internado en un hospital $(0,92 ; 0,57$ a 1,5), y sí se asoció a un aumento en la incidencia de nauseas (RR: 1,57; 1,14 a 2,15 ; NND 28*) y vómitos (RR: 2,$43 ; 1,75$ a 3,38; NND $\left.22^{*}\right)$. En niños tampoco disminuyó la probabilidad de internación (RR: 1,92; IC95\% 0,7 a 5,23), y sí aumentó la incidencia de vómitos (RR: 1,7; IC95\%: 1,23 a 2,35; NND: 19*). El uso de profilaxis no mostró eficacia para prevenir las internaciones hospitalarias (1,12; IC95\%: 0,66 a 1,94), y sí aumentó la incidencia de nauseas $(1,18 ; 1,05$ a 1,33; NND: 32*) y vómitos $\left(1,96 ; 1,2\right.$ a 3,2 ; NND: $\left.25^{*}\right)$. Por el contrario, en adultos, el tratamiento con zanamivir se asoció a una menor incidencia de náuseas y vómitos (RR: 0,6; 0,39 a 0,94; NNT: 62*).

\section{Conclusiones}

La profilaxis con oseltamivir y zanamivir tiene eficacia para reducir la incidencia de gripe sintomática. Estas drogas no han mostrado eficacia para reducir en forma clínicamente relevante la duración de la sintomatología gripal ni la incidencia de complicaciones graves ni la probabilidad de ser internado en un hospital.

Transparencia: el autor principal afirma que este manuscrito es un relato honesto, preciso y transparente del estudio que se informa, que no se ha omitido ningún aspecto importante, y que se han explicitado las discrepancias identificadas. 


\section{Comentario}

Estas drogas antivirales son comúnmente empleadas y almacenadas para el tratamiento de los pacientes con gripe estacional y pandemica ${ }^{(1)}$ y para la profilaxis de sus contactos y vale destacar que, tanto la Organización Mundial de la Salud (OMS) como el Centro de Control de Enfermedades de EE.UU. (CDC), habían declarado al oseltamivir como una "droga esencial" (2)(3). Estas recomendaciones estaban respaldadas por los resultados de investigaciones que habían "documentado" su supuesta eficacia para reducir la incidencia de complicaciones y de contagio de la gripe, pero que contenían un alta probabilidad de sesgo de información*, lo que motivó una campaña que duró cuatro años y permitió al grupo investigador que lideró el trabajo que acabamos de resumir, que contara con los documentos completos de los informes de todos los estudios clínicos ${ }^{(4)}$. En 2013 Roche accedió a los informes completos de los estudios de oseltamivir y GlaxoSmithKline, los de zanamivir. En la evaluación de estos documentos se llego a la conclusión de que había considerables problemas en el diseño, realización, reporte y disponibilidad en muchos de los trabajos. El estudio WV15799 que es con el cual la OMS justifica el almacenamiento del oseltamivir ya que prevendría la trasmisión de gripe desde los casos índices, se vio que tiene un diseño pobre, en el cual no se trata a los casos índices ni se evalúa la presencia viral en expuestos asintomáticos. Vale destacar que el informe de la FDA es el único que declara que la eficacia de ambos fármacos para la prevención y el tratamiento de los síntomas son modestos, y que no aseguran la interrupción de la propagación persona a persona, ni la prevención de la neumonía ${ }^{(5)}$.

\section{Conclusiones del comentador}

El tratamiento de la gripe con antivirales mejora mo-destamente los síntomas, con un aumento de la probabilidad de efectos adversos por parte del oseltamivir. Salvo por la disminución de la incidencia de "neumonía no verificada" (un resultado cuestionable si los hay), no reduciría el riesgo de ninguna complicación seria. Celebramos poseer como insumo para nuestra toma de decisiones la primera revisión sistemática realizada sobre información completa y de primera mano sobre la información en cuestión.

Francisco Peper [ Servicio de Medicina Familiar y Comunitaria del Hospital Italiano de Buenos Aires. francisco.peper@hospitalitaliano.org.ar ]

Peper F. Eficacia del tratamiento y la profilaxis de la gripe con oseltavimir o zanamivir. Evid Act Práct Ambul. 2014, 17(2). Abr-Jun. 56-57. Comentado de: Jefferson T. y col. Oseltamivir for influenza in adults and children: Systematic review of clinical study reports and summary of regulatory comments. BMJ 2014;348:g2545. Heneghan C y col. Zanamivir for influenza in adults and children Systematic review of clinical study reports and summary of regulatory comments. BMJ 2014; 348:g2547.

\section{Referencias}

1. Ministerio de Salud y expertos avalan la eficacia del oseltamivir para el tratamiento de la gripe - http://www.msal.gov.ar/prensa/index.php/noticias/noticias-de-la-semana/1939ministerio-de-salud-y-expertos-avalan-la-eficacia-del-oseltamivir-para-el-tratamiento-de-la-gripe\#sthash.5WDjOeCd.dpuf

2. WorldHealthOrganization.WHO model list of essential medicines.Adults, 18th edn (Apri2013). RevisedOct 2013. http://apps.who.int/iris/bitstream/10665/93142/1/EML_18_eng.pdf

3. World Health Organization. WHO model list of essential medicines for children. 4th list (April 2013). Revised Oct 2013. http://apps.who.int/iris/bitstream/10665/93143/1/EMLc 4 eng.pdf

4. Jefferson T y col. Neuraminidase inhibitors for preventing and treating influenza in healthy adults and children. Cochrane Database Syst Rev 2014;4:CD008965.

5. Jefferson T y col. Neuraminidase inhibitors for preventing and treating influenza in healthy adults and children. Cochrane Database of Systematic Reviews 2014 , Issue 4 . Art. No.: CD008965. DOI: 10.1002/14651858.CD008965.pub4 - See more at: http://summaries.cochrane.org/CD008965/regulatory-information-on-trials-of-oseltamivir-tamiflu-andzanamivir-relenza-for-influenza-in-adults-and-children\#sthash.gaNR6dYa.dpuf 